Later another infective theory came to the fore. P. Le Gac, ${ }^{10}$ interested in rickettsial disorders as a result of his work in the French Colonial Service, advanced the view that multiple sclerosis is an infectious disease produced by a rickettsia. In support of his theory he gave serological data on 27 cases, 23 of which showed positive agglutination reactions to various forms of rickettsiae. He suggested that the lesions in multiple sclerosis are a form of rickettsial endarteritis with local tissue anoxia, subsequent nerve damage, later neuroglial phagocytosis, and finally replacement of nerve tissue. In a later paper he ${ }^{11}$ mentioned 14 negative agglutinations out of a total of 52 patients and explained that certain patients "who are suffering from a physiological deficiency state are unable to produce antibodies and so give negative reactions". Putting this theory into practice, he treated a number of patients with a regimen aimed at neutralizing the organism with broad-spectrum antibiotics given in successive months for the first twelve days in each month. ${ }^{12}$ Simultaneously he urged what he called the "elimination of toxins" by hot seaweed baths, the stimulation of the cardiovascular system by camphor and nikethamide, and restoration of the patient's general state by the administration of calcium, testosterone, and an infusion of Quinton's plasma (diluted sea-water). Cure was said to be aided by acetylcholine injections and by draughts of sweetened infusions compounded of wild cherry stalks, maize whiskers, and couch grass, while further benefit might result from taking the well-known natural Vitel water. Le Gac has also suggested that amyotrophic lateral sclerosis, Parkinsonism, and other diseases of the nervous system are due to rickettsial infection and may respond to this regimen.

The investigation reported by Professor E. J. Field and Miss Mavis Chambers ${ }^{13}$ at page 30 of the B.M.F. last week is therefore to be welcomed for its careful analysis of the scientific basis of the rickettsial theory. It seems that the serological evidence adduced by Le Gac is open to considerable doubt and that the findings in normal controls do not differ significantly from those in cases of multiple sclerosis. Field and Chambers draw attention to the fact that Le Gac has so far not produced any reports of controlled trials and also to the evidence provided by a number of patients who have received the treatment but have not had any signifi-

1 Marie, P., Leçons sur les Meladies de la Moelle, Paris, Masson, 1892.

2 Millar, H. J., Vas, C. J., Noronha, M. J., Liversedge, L. A., and Rawson, M. D., Lancet, 1967, 2, 429.

3 Miller, H. G., Newell, D. J., Ridley, A. R., and Schapira, K., British Medical fournal, 1962, 1, 1726.

4 Putnam, T. J., Research Publications, Association for Research in Nervous and Mental Disease, 1950, p. 588.

5 Schumacher, G. A., Fournal of the American Medical Association, 1950, 143, 1059, 1146, 1241.

Swank, R. L. Archives of Neurology and Psychiatry, 1955, 73, 631.

7 Swank, R. L., Archives of Neurology and Psychiatry, 1955, 73, 631 . Hachen.

British Medical fournal, 1958, 2, 215.

Shubladze, A. K., and Dick, G. W. A., British Medical fournal, 1958, 2, 245.

10 Le Gac, P., Comptes Rendus Hebdomadaires des Séances de l'Académie des Sciences, 1960, 250, 2299, 2474.

11 Le Gac, P., Fournal de Médecine de Bordeaux et du Sud-Ouest, 1960, $137,346$.

12 Le Gac, P., fournal de Médecine de Bordeaux et du Sud-Ouest, 1960, $137,577$.

13 Field, E. J., and Chambers, M., British Medical fournal, 1970, 1, 30.

14 Ross, C. A. C., Lenman, J. A. R., and Melville, I. D., British Medical fournal, 1969, 3, 512 .

15 Miller, H. G., Newell, D. J., Ridley, A., Lancet, 1961, 1, 127

16 Alexander, L., and Cass, L. J., Annals of Internal Medicine, 1963, 58, 454.

17 Rawson, M. D., Liversedge, L. A., and Goldfarb, G., Lancet, 1966, 2, 1044.

18 Rawson, M. D., and Liversedge, L. A., Lancet, 1969, 2, 222. cant alteration in the course of their disease. This clinical evidence can be supported by other clinical neurologists who have seen such cases. It seems, therefore, that the twin scientific and therapeutic supports of the Le Gac theory are fragile.

In the face of a disorder that is ill understood and so tragic in its effects many serious and well-intentioned people, both lay and medical, press clinicians to carry out clinical trials of various remedies. The "try-anything" philosophy is indeed very understandable, and it is difficult to produce arguments to counter it. But future attempts must begin with a scientifically reasonable idea (and Le Gac's idea was reasonable) and then proceed to thorough therapeutic trial as exemplified by the three-cities trial of corticotrophin. ${ }^{2}$

Is the present position all dark? So far there is indeed no cure, but treatment is helpful. Though relapses cannot be abolished, the residual effect of an acute attack can be minimized. The relation between intercurrent infection and relapse of the disease may be indirect and involve immune mechanisms. ${ }^{14}$ Some workers ${ }^{1516}$ have commented on the apparent rapidity with which acute relapses in multiple sclerosis appeared to respond to the administration of cortisone, prednisone, or corticotrophin. M. D. Rawson and colleagues $^{17}{ }^{12}$ studied the clinical evolution of two groups of cases of retrobulbar neuritis and showed that the response in 25 treated cases was both more rapid and better than in 25 controls. This was a double-blind trial and appears to be statistically valid at least for the short-term result. If the results of treating retrobulbar neuritis can be generalized to acute attacks elsewhere in the nervous system, it does seem reasonable to give the patient a short course of corticotrophin in one form or another as advised by Rawson and his colleagues. ${ }^{18}$ But, as Millar and his colleagues showed, ${ }^{2}$ continuous corticotrophin therapy (at least in a dosage of 20 units per day) was not effective in abolishing relapses. In addition we know that vitamin $B_{1}$ and vitamin $B_{12}$ are essential components of myelin. On the assumption that myelinated fibres have been only partly destroyed by the disease process it may be reasonable to give a short course of both vitamins for two or three months after any acute attack.

Apart from these suggestions the treatment of multiple sclerosis must be symptomatic, with management of spasticity, bladder symptoms, and such other disabilities over which the patient may be helped. Meantime the struggle to find the real cure goes on, and the criteria by which it is tested should be rigorous and strictly observed.

\section{Learning and Aversion}

Aversion therapy is one of a number of treatments based on principles of learning. It sets out to inhibit patterns of behaviour which the patient finds undesirable and wishes to control, and it does so by linking the behaviour pattern repeatedly with an unpleasant stimulus, so that a conditioned reflex is established.

The best-known form of aversion therapy is still the use of apomorphine or emetine in the treatment of alcoholism. Administration of apomorphine, which acts as an unconditional stimulus for nausea and vomiting, is repeatedly asso- 
ciated with the drinking of alcohol (the conditional stimulus) until eventually drinking alcohol itself results in severe nausea. This form of aversion therapy is unpleasant and not free from danger. It is also difficult to time the unconditional and conditional stimuli with the accuracy which is required if conditioning is to result. Moreover, after an initial period of enthusiasm for the treatment, a controlled trial ${ }^{1}$ failed to show a definite advantage over disulfiram (Antabuse) and group treatment. The technical details of the aversion therapy employed in this trial have been criticized, ${ }^{2}$ but there has been no definite evidence to refute its conclusions. At any rate the use of this method of aversion therapy for alcoholism has declined, though it may still have a place in the treatment of selected patients.

Two recent advances have revived interest in aversion therapy. The first is the replacement of apomorphine as the aversive stimulus by mild electric shocks, usually delivered to the forearm by a small battery-operated shock-box. These constitute a much less unpleasant procedure than the original method and yet one which appears to be equally, or even more, effective, because shocks can be repeated far more frequently and timed more accurately than the pharmacological procedures (careful timing is an essential part of any conditioning treatment). Secondly, treatment has been shown to be applicable not only to alcoholism but to other conditions which have proved very difficult to treat by other means.

Recent work has been particularly concerned with the sexual deviations, particularly homosexuality, fetishism, and transvestism. ${ }^{34}$ Because these conditions are uncommon and the treatment is new, it has not yet been possible to collect substantial comparative controlled series. However, much has been learnt by careful studies in which patients acted as their own controls. An important by-product of these investigations has been the development of more precise methods of measurement of the changes during treatment, especially physiological assessments ${ }^{5}$ and the measurements of attitudes. ${ }^{6}$ In this way the value of electric aversion therapy for transvestism and fetishism has been established with reasonable precision, even though far fewer patients have been treated than was the case with alcoholism. Nevertheless, further comparative trials are required before a final assessment can be reached.

At page 82 of the B.M.f. this week Dr. M. A. Hamilton Russell describes another interesting application of electric aversion therapy-namely, a preliminary investigation of its effect on cigarette smoking. An effective treatment could be of considerable help to heavy smokers. Many methods of curbing heavy smoking have been tried, but so far there is no convincing evidence that any is more effective than strong encouragement or other factors which strengthen the patient's motivation. Russell modelled his investigation on an earlier investigation of aversion therapy for transvestism, ${ }^{7}$ and he introduced measurements of changes during and after treatment as well as counting the number of suc-

1 Wallerstein, R. S., ed., The Hospital Treatment of Alcoholism, London, Imago Press, 1957.

2 Eysenck, H. J., Experiments in Behaviour Therapy. London, Pergamon Press. 1964.

3 Bancroft, J. H. J., and Marks, I. M., Proceedings of the Royal Society of Medicine, 1968, 61, 796.

4 MacCulloch, M. J., British Medical fournal, 1967, 2, 594.

5 Bancroft, J. H. J., Jones, H. G., and Pullin, B. R., Behaviour Research and Therapy, 1966, 4, 239.

6 Marks, I. M., British fournal of Medical Psychology, 1968, 41, 47.

7 Marks, I. M., and Gelder, M. G., British Fournal of Psychiatry, 1967, 113, 711 . cesses and failures. He measured not only the number of cigarettes smoked but also changes in the patient's attitudes to smoking, using a psychological test known as the semantic differential. His results are sufficiently encouraging to demand further controlled study, but they are difficult to assess because smokers who volunteer for an unpleasant form of treatment are almost certainly more highly motivated than the average. Motivation is, of course, known to be very important in deciding whether the smoker gives up or not. Moreover, 35\% of his patients failed to complete treatment, so that of those who started only $42 \%$ were judged to have improved at follow-up. As Russell points out, $20-30 \%$ of smokers give up without treatment, and it is difficult to assess the clinical significance of these differences when motivation may differ and numbers are small. Nevertheless, this pilot study is particularly welcome because it has been carried out most carefully and indicates the lines on which a more extensive controlled investigation could be pursued.

Though evidence is accumulating that aversion therapy is a valuable addition to the treatment of these selected disorders, it is still not certain how clinical changes come about. The simple explanation, on which aversion treatment was founded, is that conditioned reflexes build up and inhibit the behaviour which the patient wishes to control. If this is true, successful aversion therapy with electric shocks should be clearly associated with the build-up of conditioned anxiety. However, when this association was specifically sought, no relation was found between amount of conditioned anxiety during treatment and success of outcome. ${ }^{3}$ Indeed, many patients who showed no conditioned anxiety during treatment did well. However, there is a relation between change of attitudes during treatment and successful outcome, and this attitude change is maximal in the first few days of treatment, before the formation of conditioned reflexes would be expected to be complete. ${ }^{7}$ It is therefore of interest that Russell, who also measured attitude changes, found that attitudes had changed maximally after the first four sessions of treatment.

Many clinicians have thought that explanations based on learning theories present a considerably oversimplified picture of the changes which they see in patients receiving aversion therapy. Further research into the cognitive changes which follow treatment may help us to understand more about its mechanisms and perhaps lead eventually to less unpleasant ways of bringing about the same essential changes.

\section{Fibrinolysis and Menstrual Bleeding}

Over the last few years the development of immunological techniques has allowed further study of the mechanisms and consequences of fibrinolysis. Menstruation is basically a vascular phenomenon localized to the uterus, and fibrinolytic enzymes have an essential role in the process.

The non-coagulability of menstrual blood has been shown to be the result of primary clotting and the simultaneous breakdown of the fibrin by the proteolytic enzyme plasmin, which is formed by activation of the fibrinolytic system. ${ }^{1}$ A. S. Todd ${ }^{2}$ studied the fibrinolytic activity of normal endometrium. He found a constant focal fibrinolytic activity in the 